\title{
Antihypertensive effects of the hydro- ethanol extract of Senecio serratuloides DC in rats
}

\author{
Charlotte Mungho Tata', Constance Rufaro Sewani-Rusike', Opeoluwa Oyehan Oyedeji², Ephraim Tobela Gwebu ${ }^{3}$, \\ Fikile Mahlakata ${ }^{4}$ and Benedicta Ngwenchi Nkeh-Chungag ${ }^{5 *}$
}

\begin{abstract}
Background: Senecio serratuloides DC is used in folk medicine for treating hypertension, skin disorders, internal and external sores, rashes, burns and wounds. This study aimed at investigating the antihypertensive effects of the hydroethanol extract of S. serratuloides (HESS) in N-Nitro-L-arginine methyl ester (L-NAME) induced hypertension in rats. Methods: Acute toxicity of HESS was first determined to provide guidance on doses to be used in this study. Lorke's method was used to determine safety of the extract in mice. Female Wistar rats were treated orally once daily with LNAME $(40 \mathrm{mg} / \mathrm{kg})$ for 4 weeks and then concomitantly with L-NAME $(20 \mathrm{mg} / \mathrm{kg})$ and plant extract $(150 \mathrm{and} 300 \mathrm{mg} / \mathrm{kg})$, captopril $(20 \mathrm{mg} / \mathrm{kg})$ or saline as per assigned group for 2 weeks followed by a 2-week period of assigned treatments only. Blood pressure was monitored weekly. Lipid profile, nitric oxide, renin and angiotensin II concentrations were determined in serum while mineralocorticoid receptor concentration was quantified in the kidney homogenate. Nitric oxide (NO) concentration was determined in serum and cardiac histology performed.
\end{abstract}

Results: HESS was found to be non-toxic, having a $L_{50}$ greater than $5000 \mathrm{mg} / \mathrm{kg}$. Blood pressure increased progressively in all animals from the second week of L-NAME treatment. HESS treatment significantly and dose-dependently lowered systolic blood pressure $(p<0.001)$, diastolic blood pressure $(p<0.01)$, low density lipoprotein cholesterol $(p<0.01)$ and triglycerides $(p<0.01)$. It significantly prevented L-NAME induced decrease in serum angiotensin II $(p<0.01)$, high density lipoprotein cholesterol $(p<0.001)$ and serum nitric oxide concentrations $(p<0.001)$. HESS also significantly $(p<0.01)$ prevented collagen deposition in cardiac tissue.

Conclusion: The hydro-ethanol extract of Senecio serratuloides showed antihypertensive, antihyperlipidemic and cardioprotective effects in rats thus confirming its usefulness in traditional antihypertensive therapy and potential for antihypertensive drug development.

Keywords: Senecio serratuloides, N-nitro-L-arginine methyl ester, Hypertension, Lipid profile

\section{Background}

One in three adults worldwide has hypertension (HTN) and the prevalence has been shown to increase with age [1]. Hypertension is a growing public health concern in sub-Saharan countries where it was previously not reported. In this population, HTN is characterized by a rapid onset, poor control and an early onset of target organ damage [2]. Poor control of HTN contributes

\footnotetext{
* Correspondence: bnkehchungag@wsu.ac.za

${ }^{5}$ Department of Biological Sciences, Faculty of Natural Sciences, Walter Sisulu University, Mthatha 5117, South Africa

Full list of author information is available at the end of the article
}

enormously to the burden of cardiovascular diseases (CVDs) and associated morbidity and mortality. Indeed, a relevant systemic meta-analysis showed that every 10 $\mathrm{mmHg}$ reduction of systolic blood pressure (BP) was accompanied by a significant decrease in the risk for CVD [3]. Several classes of anti-hypertensive medications have been developed with the aim of reducing BP and consequently the associated risks [4]. However, affordability and availability of pharmaceutical antihypertensive medications are important challenges especially in rural African communities thus affecting compliance with treatment regiments. Importantly, reported side effects of pharmaceutical

(c) The Author(s). 2019 Open Access This article is distributed under the terms of the Creative Commons Attribution 4.0 International License (http://creativecommons.org/licenses/by/4.0/), which permits unrestricted use, distribution, and reproduction in any medium, provided you give appropriate credit to the original author(s) and the source, provide a link to the Creative Commons license, and indicate if changes were made. The Creative Commons Public Domain Dedication waiver (http://creativecommons.org/publicdomain/zero/1.0/) applies to the data made available in this article, unless otherwise stated. 
drugs [5] and the belief that plant medicines are less toxic are contributing to the preference of plant extracts over pharmaceutical drugs [6].

In rural South African communities, medicinal plants are used for BP management. S. serratuloides DC, is an Asteraceae commonly found in areas of South Africa which receive summer rainfalls. S. serratuloides is a perennial which grows from a woody root/stem, has serrated leaves and tiny yellow flowers which are clustered at the terminals. It is used in folk medicine for treatment of various ailments [7, 8]. A recent ethnobotanical survey of medicinal plants used for self-medication by lay people of Maputaland and Northern Kwazulu-Natal, South Africa, showed that S. serratuloides was one of the most commonly used plants for treatment of HTN $[9,10]$. Furthermore, S. serratuloides was reportedly used in combination with several medicinal plants to prepare concoctions for hypertension treatment [11]. Importantly none of the plant combinations which included $S$. serratuloides had been previously described. Other authors from the same region indicated that S. serratuloides was among the most used plants for respiratory infections [12] thus confirming the fact that this plant has extensive uses. Although S. serratuloides is widely used in the South African traditional medicine, it's medicinal properties have not received much scientific attention. Extracts of this plant are reported to have antioxidant, analgesic, anti-inflammatory and wound healing activities $[13,14]$. Due to the efficacy of the plant extract in treating various diseases it is traditionally referred to as the 'two day cure' plant. Although there is no scientific report on the use of S. serratuloides in the treatment of hypertension, another member of the Genus, Senecio nutans which is native to South America has demonstrated antihypertensive and hypotensive effects in rats [15]. The health benefits of the Senecios may be associated with their rich flavonoid and phenol contents [16]. Indeed, studies have demonstrated the usefulness of plant flavonoids in the prevention of atherosclerosis and hyperlipidemia [17] though these properties have not been evaluated for S. serratuloides.

Even though S. serratuloides is popular in South African traditional medicine, only its antimicrobial, analgesic and anti-inflammatory/wound healing properties have been investigated $[13,14]$. Its potential usefulness in the management of any of the chronic diseases of lifestyle has not been studied. To our knowledge, this is will be the first study reporting on the antihypertensive effects of $S$. serratuloides. In this study we used L-NAME to induce hypertension. L-NAME is an inhibitor of nitric oxide synthase activity and consequently the synthesis of nitric oxide (NO). Chronic administration of L-NAME results in generalized reduction of NO resulting in endothelial dysfunction which is observed in the early phase of hypertension [18]. L-NAME induced hypertension is associated with activated sympathetic tone and generalized vasoconstriction [19]. This experimental model of hypertension has several similarities with human hypertension in the African population who demonstrate increased sympathetic activation, salt sensitivity and decreased NO dependent vasodilation [20] and high rate of target organ damage [21]. Therefore, the aim of the study was to investigate the safety and antihypertensive properties of the hydroethanol extract of S. serratuloides (HESS) in the L-NAME-induced hypertensive rat model and the effect of treatment on selected target organs.

\section{Methods \\ Reagents}

Triglyceride reagent (TR212), Low density lipoprotein reagent (CH2656), High density lipoprotein reagent (CH2655) and Triglyceride reagent (TR210) (Randox Laboratories Ltd., UK); Renin ELISA kit (E-EL-R0030) and Angiotensin II ELISA kit (E-EL-R1430) (Elabscience, PRC); Bradford reagent, Fastcast acrylamide kit, Turbo transfer kit (170-4270) and Clarity western ELC substrate (170-5060) (Bio-Rad Laboratories, USA); Anti-mineralocorticoid receptor antibody (ab2774), anti-ß-actin antibody (ab8227) and Goat anti-rat IgG H\&L (HRP) (ab205719) (Abcam Laboratories Inc., USA) Protease inhibitor (S8820-20TAB), RIPA buffer (R0278), $\mathrm{N} \omega$-Nitro-L-arginine methyl ester and $B$-mercaptoethanol (Sigma, USA); stains (Harris haematoxylin, eosin and picrosirius red) and solvents (ethanol, glacial acetic acid, methanol xylene) were of analytical grade.

\section{Plant material and extraction}

Senecio serratuloides was supplied by Mr. Fikile Mahlakata, a traditional healer in Lusikisiki, South Africa and authenticated in the KEI Herbarium of Walter Sisulu University where a voucher specimen (Tata 1/13967) was deposited. Plant material was air dried in the laboratory, crushed and exhaustively extracted in $70 \%$ ethanol which extracts a good number of polar and non-polar secondary metabolites. Ethanol was recovered under vacuum using a rotary evaporator (Heidolph Laborota 4000, Germany) at $35^{\circ} \mathrm{C}$ and then oven dried at the same temperature. The plant extract was then stored in a refrigerator and reconstituted in distilled water before use.

\section{Animals}

Swiss albino female mice weighing $20-25 \mathrm{~g}$ were used for acute toxicity studies while female Wistar rats weighing 200-240 g were used for HTN study. Animals were procured from South African Vaccine Producers (Johannesburg, South Africa) and housed in cages in the Walter Sisulu University animal holding facility. Room temperature was maintained at $24^{\circ} \mathrm{C}$ and natural light was used for 
lighting. Animals had free access to rat chow (Epol-SA) and tap water. All animal procedures were carried out in line with the South African National Standards: The care and use of animals for scientific purposes [22].

\section{Acute oral toxicity}

Acute toxicity study was conducted in accordance with Lorke's method as described by Bulus et al., [23]. The study was conducted in two phases using a total of sixteen mice. The geometric mean of the least dose that killed an animal and the highest dose that did not kill any animal was considered as the median lethal dose $\left(\mathrm{LD}_{50}\right)$ :

$$
L D_{50}=\sqrt{ }\left(D_{0} \times D_{100}\right) .
$$

Where $\mathrm{D}_{0}$ is the highest dose that caused no mortality and $\mathrm{D}_{100}$ is the lowest dose that caused mortality.

\section{Hypertension study design}

Animals were randomized into five treatment groups of six animals per group $(n=6)$ as follows:

$$
\begin{aligned}
& \text { NT - normotensive control. } \\
& \text { LN - L-NAME treatment only. } \\
& \text { CPT + LN - CPT (Captopril }(20 \mathrm{mg} / \mathrm{kg})) \text {. } \\
& \text { HESS150 + LN - HESS }(150 \mathrm{mg} / \mathrm{kg}) \text {. } \\
& \text { HESS300 + LN - HESS }(300 \mathrm{mg} / \mathrm{kg}) \text {. }
\end{aligned}
$$

Experiments were carried out according to the protocol described by Lane, [24] with slight modification. Except for the normotensive group that was treated with normal saline only, rats from the other groups were first treated with L-NAME $(40 \mathrm{mg} / \mathrm{kg})$ for 4 weeks and then the $\mathrm{LN}$, CPT, HESS150 and HESS300 groups were co-treated with normal saline, captopril or extract $(150$ and $300 \mathrm{mg} / \mathrm{kg}$ ) respectively and L-NAME $(20 \mathrm{mg} / \mathrm{kg})$ as per assigned groups for 2 weeks. Finally, in the last 2 weeks, LN treatment was discontinued for all groups, and the NT and LN groups were treated with normal saline, the $\mathrm{CPT}$ group with captopril and HESS groups with the extract. Summary of study timeline is shown in Fig. 1.

\section{Measurement of blood pressure}

Blood pressure was measured in conscious rats, using non-invasive tail-cuff plethysmography ${\left(\mathrm{CODA}^{\mathrm{mm}}\right.}^{\mathrm{m}} 8$ Non-Invasive Blood Pressure System, Kent Scientific Corporation, USA) as per manufacturer's instructions. Systolic blood pressure (SBP), diastolic blood pressure (DBP) and heart rates (HR) were measured weekly at 8 am. Rats with $\mathrm{SBP} \geq 200 \mathrm{mmHg}$ and $\mathrm{DBP} \geq 160 \mathrm{mmHg}$ were considered hypertensive.

\section{Termination of treatment}

Treatment was stopped 2 days before the termination in order to study the long-term effects of the extract without involvement of the effects of acute administration $[25,26]$. Rats were fasted for $16 \mathrm{~h}$, weighed and terminated individually by carbon dioxide inhalation followed by cardiac puncture for blood collection. Collected blood was placed in ST vacutainers, mixed and incubated in upright positions at room temperature for $45 \mathrm{~min}$ and centrifuged at 1300 RCF for $15 \mathrm{~min}$ to obtain serum. Kidneys and hearts were harvested and divided into two portions half of which was fixed in $10 \%$ buffered formalin and the other half stored at $-20^{\circ} \mathrm{C}$ for later analysis.

\section{Determination of lipid profile of treated animals}

Triglycerides, low density lipoprotein cholesterol (LDL) and high density lipoprotein cholesterol (HDL), were measured using kits from Randox Laboratory (Randox co. UK) following protocol described by manufacturer. Total cholesterol and very low density lipoprotein (VLDL) were calculated using Friedewald equation as described by Vuilleumier et al., (2010) [27]:

$\mathrm{VLDL}=\mathrm{TG} / 5$.

$\mathrm{TC}=\mathrm{HDL}+\mathrm{LDL}+\mathrm{VLDL}$.

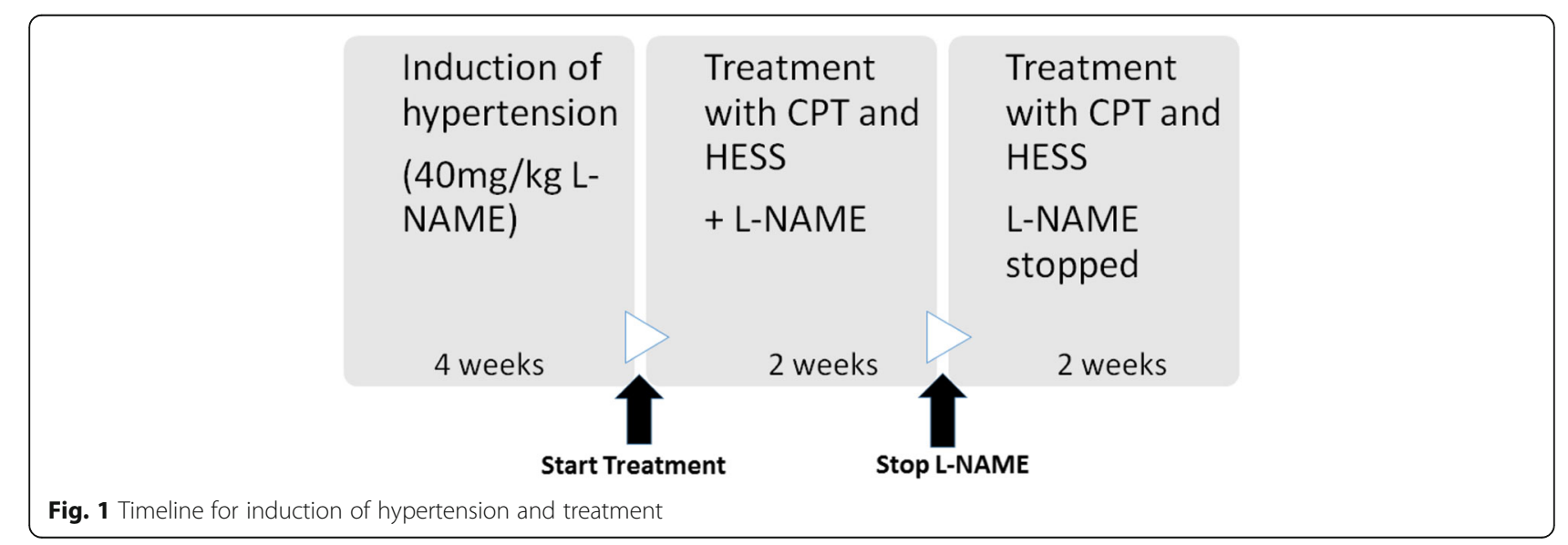




\section{Determination of renin and angiotensin II concentration in serum}

Renin and Ang II concentrations were determined in serum by enzyme linked immunosorbent assay (ELISA) using pre-coated commercial kits (Elabscience, PRC). Renin concentration was determined via sandwich-ELISA (E-EL-R0030) while angiotensin II concentration was determined by competitive ELISA (E-EL-R1430).

\section{Determination of mineralocorticoid receptor concentration in kidney homogenate}

Mineralocorticoid receptors were separated and identified by western blotting using commercial kits (Bio-Rad laboratories, USA). Briefly, proteins in kidney homogenate were quantified and separated by electrophoresis and blotted onto a nitrocellulose membrane. The membrane was incubated with rat anti-mineralocorticoid antibody (ab2774) followed by incubation with horseradish peroxidase (HRP)-conjugated secondary antibodies; goat anti-rat IgG H\&L (HRP) (ab205719) (Abcam, Laboratories Inc., USA) for $1 \mathrm{~h}$ at room temperature and $25 \mathrm{rev} / \mathrm{min}$. Bound antibodies were detected by chemiluminiscence using Clarity Western enhanced chemiluminiscence (ECL) substrate (170-5060) and imaging was done using ChemiDoc Touch Imaging System (Bio-Rad laboratories, USA). Analysis of images was performed using Image Lab software (Bio-Rad laboratories, USA) and bands for mineralocorticoid receptors were normalized using housekeeping proteins (ß-actin, ab8227).

\section{Determination of NO levels in serum and tissue homogenates}

Nitric oxide was quantified indirectly using Griess reagent (5\% phosphoric acid, 1\% N-(1-naphthyl) ethylenediamine (NEDD) and $1 \%$ sulfanilamide) and $\mathrm{NaNO}_{2}$ standard curve. In the assay, acidified $\mathrm{NO}_{2}$ produced a nitrosating agent which reacted with sulfanilic acid to produce diazonium ion which then coupled with NEDD to form a chromophoric azo-derivative which was quantified spectrophotometrically (Bio-Rad 680, USA) at $540 \mathrm{~nm}$.

\section{Cardiac histology}

Heart sections were fixed in $10 \%$ buffered formalin, embedded in paraffin wax, sectioned in $5-\mu \mathrm{m}$ slices and stained with haematoxylin/eosin [28] and picrosirius red stain [29]. These sections were examined using a digital light microscope (Leica DMD108) at 20X and 40X magnifications and images captured. Morphometry was used to determine areas of cardiomyocyte thickening as previously described [30]. Semi-quantification of collagen was done using $100 \mu \mathrm{m} \times 100 \mu \mathrm{m}$ images. Image J (NIH.gov/ ij/) scientific image analysis software was used for density quantification as previously described [31]. Measurements were performed on 4 different slides per sample.

\section{Statistical analysis}

Statistical analysis was carried out using GraphPad Prism version 5.03 for Windows (GraphPad Software, San Diego, CA, USA). One-way analysis of variance (ANOVA) followed by Tukey's posthoc test for multiple comparisons was performed to determine differences between treatment groups. A $p$-value less than 0.05 was considered statistically significant. Results were expressed as mean \pm standard error of the mean (SEM).

\section{Results}

\section{Acute toxicity results}

Animals did not show any signs of toxicity after treatment with HESS in line with the $\mathrm{LD}_{50}$ of HESS greater than $5000 \mathrm{mg} / \mathrm{kg}$ that was obtained. Wellness parameters such as sleep, behavioral pattern, skin, fur and appetite which are used for evaluation of toxicity were found to be normal up to a dose level of $5000 \mathrm{mg} / \mathrm{kg}$ during the entire period of observation. In addition, there was no relative difference, observed in the body weights of treated and control animals after two weeks of observation.

\section{Effect of HESS on systolic and diastolic blood pressures} Both SBP and DBP increased significantly in all treatment groups compared to NT group from weeks 2-4 of L-NAME treatment. In the subsequent weeks, co-treatment with HESS and L-NAME for 2 weeks and treatment with HESS or normal saline only for 2 more weeks revealed that in weeks 5 and 6, CPT and HESS300 significantly decreased SBP by 7 and $1 \%$ respectively compared to $13 \%$ increase in $\mathrm{LN}$ group. In week 7, CPT, HESS150 and HESS300 significantly decreased SBP by 32, 17 and $20 \%$ compared to $7 \%$ increase in $\mathrm{LN}$ group. In week 8, CPT HESS150 and HESS300 significantly decreased SBP by 26, 15 and $25 \%$ compared to $0.1 \%$ decrease in LN group (Fig. 2, panel A). Considering the effect of treatment on DBP, it was observed that in week 7, CPT, HESS150 and HESS300 significantly decreased DBP by 40, 22 and 23\% respectively compared to $16 \%$ increase in LN group. Meanwhile in week 8, CPT, HESS150 and HESS300 significantly decreased DBP by 20, 18 and $40 \%$ compared to $3 \%$ increase in LN group (Fig. 2, panel B).

\section{Lipid profile}

Results from serum lipid profile showed that L-NAME significantly decreased HDL while increasing LDL, VLDL and TG in LN group compared to NT control group. HESS150 and HESS300 significantly increased HDL compared to LN control. However only HESS300 significantly decreased LDL, VLDL and TG (Table 1).

\section{Renin and angiotensin II concentration in serum}

There was no difference $(p>0.05)$ in concentration of renin between treatment groups $(\mathrm{NT}=557 \pm 32 \mathrm{pg} / \mathrm{ml}$; 


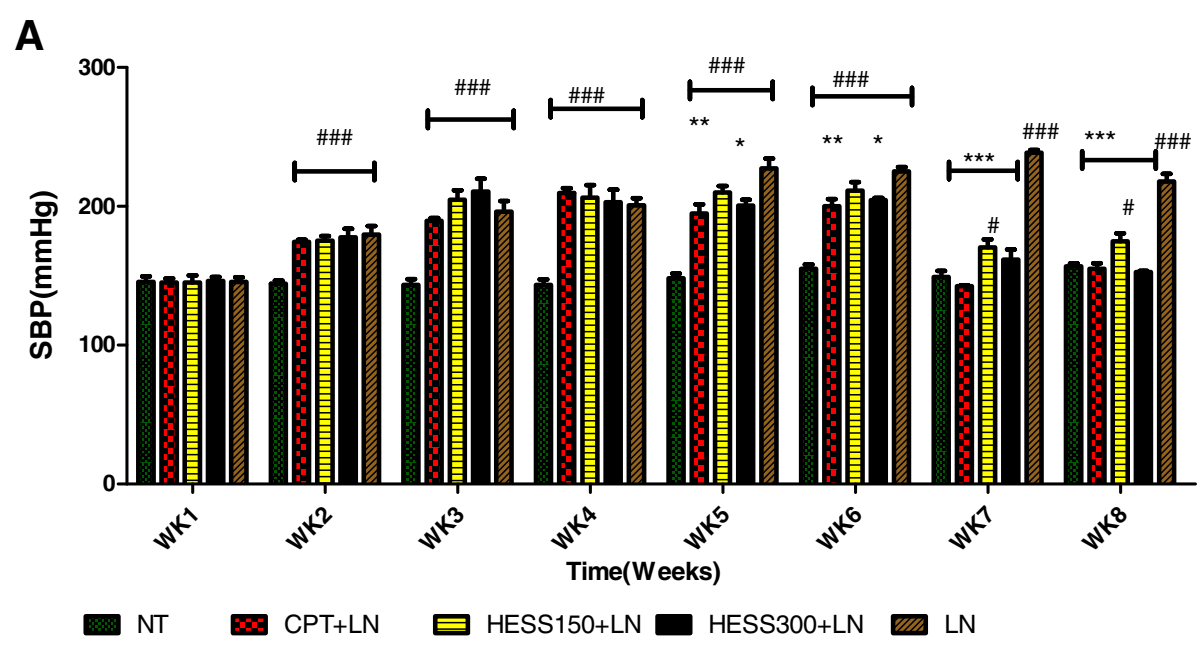

B

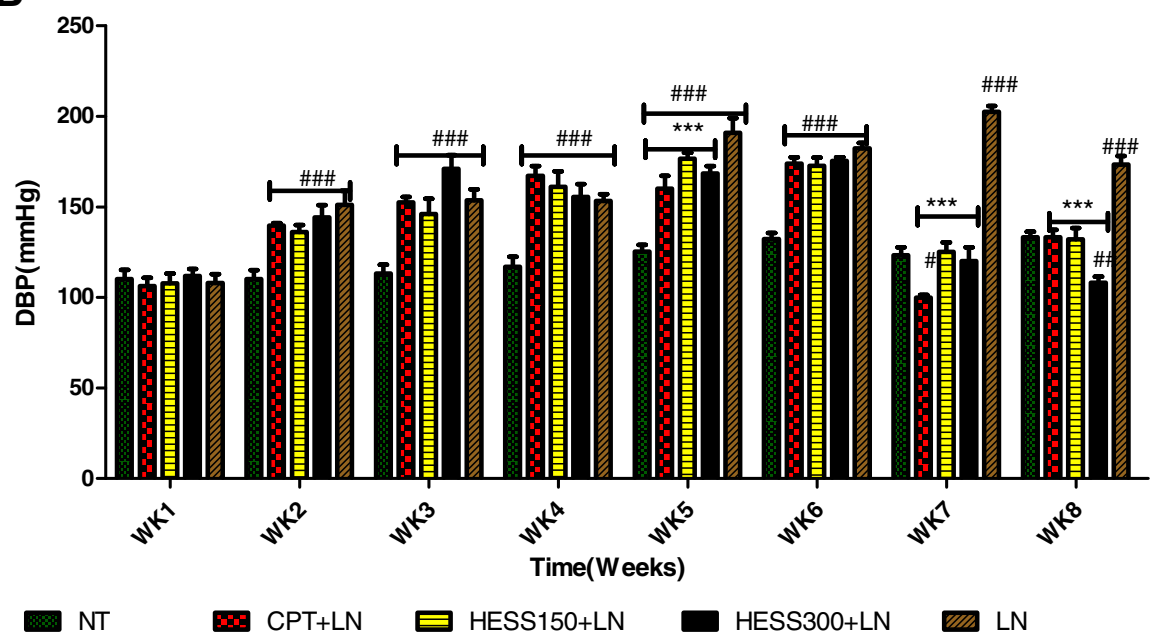

Fig. 2 Effect of HESS on SBP (Panel a) and DBP (panel b) in L-NAME induced hypertension. Values are expressed as mean \pm SEM. $n=6 ; N T=$ normotensive control; LN = L-NAME control; CPT + LN = captopril; HESS150 + LN and HESS300 + LN = hydroethanolic extract of Senecio serratuloides at 150 and 300 mg/ kg respectively. ${ }^{*} p<0.05,{ }^{* *} p<0.01,{ }^{* * *} p<0.001$ compared to L-NAME (LN) control group; \#p $<0.05$, \#\# $p<0.01$, \#\#\#p $<0.001$ compared to normotensive control group

Table 1 Effect of HESS on lipid profile in L-NAME induced hypertensive rats

\begin{tabular}{llllll}
\hline & \multicolumn{2}{l}{ Parameters $(\mathrm{mg} / \mathrm{dl})$} & & \\
\cline { 2 - 5 } & TG & $\mathrm{HDL}$ & $\mathrm{LDL}$ & $15.5 \pm 0.2$ & TC \\
\hline NT & $77.4 \pm 1$ & $61.2 \pm 5$ & $46.61 \pm 3$ & $17.3 \pm 0.4^{\#}$ & $121.3 \pm 8$ \\
HESS150 + LN & $86.5 \pm 2^{\#}$ & $50.99 \pm 2^{* *}$ & $57.98 \pm 3^{\#}$ & $124.9 \pm 6$ \\
HESS300 + LN & $69.2 \pm 1^{\# * * *}$ & $52.95 \pm 3^{* * *}$ & $46.34 \pm 4^{* *}$ & $13.8 \pm 0.3^{* * * \#}$ & $116.6 \pm 7$ \\
CPT + LN & $79.5 \pm 2$ & $35.3 \pm 4^{\# \# \#}$ & $52.4 \pm 4$ & $15.9 \pm 0.5$ & $101.5 \pm 8$ \\
LN & $86.1 \pm 2^{\#}$ & $29.4 \pm 2^{\# \# \#}$ & $64.15 \pm 2^{\# \#}$ & $17.2 \pm 0.4^{\#}$ & $110.8 \pm 5$ \\
\hline
\end{tabular}

Results are expressed as mean $\pm \mathrm{SEM}, n=6 . \mathrm{NT}=$ normotensive control group; $\mathrm{LN}=\mathrm{L}-\mathrm{NAME}$ control group; CPT $+\mathrm{LN}=$ captopril group; HESS150 + LN and HESS300 $+\mathrm{LN}=$ hydroethanolic extract of Senecio serratuloides at 150 and $300 \mathrm{mg} / \mathrm{kg}$ groups respectively. ${ }^{* *} p<0.01,{ }^{* * *} p<0.001$ compared to L-NAME (LN) control group; $\# p<0.05, \# \#<0.01, \# \# p<0.001$ compared to normotensive control group 
$\mathrm{LN}=480 \pm 21 \mathrm{pg} / \mathrm{ml} ; \mathrm{CPT}+\mathrm{LN}=550 \pm 19 \mathrm{pg} / \mathrm{ml} ; \mathrm{HESS} 150$ $+\mathrm{LN}=561 \pm 25 \mathrm{pg} / \mathrm{ml} ; \quad \mathrm{HESS} 300+\mathrm{LN}=527 \pm 29 \mathrm{pg} / \mathrm{ml}$ ). L-NAME significantly decreased Ang II concentration in LN group compared to NT group. However, HESS150 and HESS300 significantly prevented this L-NAME-induced decrease in Ang II compared to LN group (Fig. 3).

\section{Mineralocorticoid receptor concentration in kidney tissue homogenate}

It was observed that L-NAME treatment significantly increased expression of mineralocorticoid receptors in kidney homogenates of LN group compared to NT group. HESS150 + LN, HESS300 + LN and CPT + LN treatment groups had lower mineralocorticoid receptor levels although there was no significant difference compared to LN group (Fig. 4).

\section{Nitric oxide concentration in serum, heart and kidney homogenates}

In serum, L-NAME significantly decreased the concentration of NO in LN group compared to NT group. HESS300 and CPT significantly prevented L-NAME induced decrease in serum NO concentration (Fig. 5).

\section{Effect of HESS on cardiac tissue}

Figure 6 shows photomicrographs (A) of cardiac tissue samples stained with haematoxylin and eosin stain $(\mathrm{X})$, picrosirius red stain (Y) and a graph (B) of collagen concentration (\%) from semi-quantitative analysis of photomicrographs stained with picrosirius red. L-NAME induced significant fibrosis in LN treatment group compared to NT group $(0.66 \pm 0.1 \%$ vs $0.06 \pm 0.02 \%$; $p<$ $0.001)$. On the other hand, L-NAME-induced cardiac fibrosis was attenuated by treatment with HESS150 (0.34 $\pm 0.02 \% ; 0.05)$, CPT $(0.26 \pm 0.1 \%, 0.01)$ and HESS300 $(0.25 \pm 0.03 \%, 0.01)$ respectively. Haematoxylin and eosin staining revealed thickened portions of cardiomyocytes in the LN treatment group suggesting hypertrophy that was confirmed with picrosirius stain.

\section{Discussion}

Results from this study showed that the hydroethanolic extract of S. serratuloides (HESS) was not toxic and prevented L-NAME induced hypertension. HESS also prevented L-NAME induced hyperlipidemia, maintained serum angiotensin II concentration and protected target organs.

Acute toxicity of HESS was greater than $5000 \mathrm{mg} / \mathrm{kg}$. According to the toxicity guidelines by Konaté et al. [32], pharmacological substances with $\mathrm{LD}_{50}$ less than $5 \mathrm{mg} / \mathrm{kg}$ are classified as highly toxic substances, those with $\mathrm{LD}_{50}$ between $5 \mathrm{mg} / \mathrm{kg}$ and $5000 \mathrm{mg} / \mathrm{kg}$ are classified as moderately toxic substances while those with $\mathrm{LD}_{50}>5000 \mathrm{mg} / \mathrm{kg}$ are not toxic. Therefore the hydroethanolic extract of $S$. serratuloides whose $\mathrm{LD}_{50}>5000 \mathrm{mg} / \mathrm{kg}$ was considered non-toxic and safe for consumption.

Treatment with L-NAME resulted in decreased HDL and increased LDL/TG/VLDL thus corroborating the findings of Salam et al. [33] who showed that L-NAME treatment had an adverse effect on lipid profiles in treated rats. L-NAME treatment raised the concentration of LDL which in turn was capable of interfering with eNOS activity. Under normal conditions, eNOS is associated with cholesterol-enriched caveolae in endothelial cells, where its activity can be carefully regulated [34]. However, in hyperlipidemia, LDL, especially oxLDL negatively affects the activity and sub-cellular distribution of eNOS hence leading to a decrease in NO bioavailability [35, 36]. On the other hand, HDL causes activation of eNOS within the caveolae, with the resultant generation of NO [37]. Our findings showed that HESS significantly improved lipid profiles in a dose dependent manner in L-NAME treated animals indicating that HESS inhibited hypertension by reducing inactivation of eNOS by LDL and promotion of its activity by

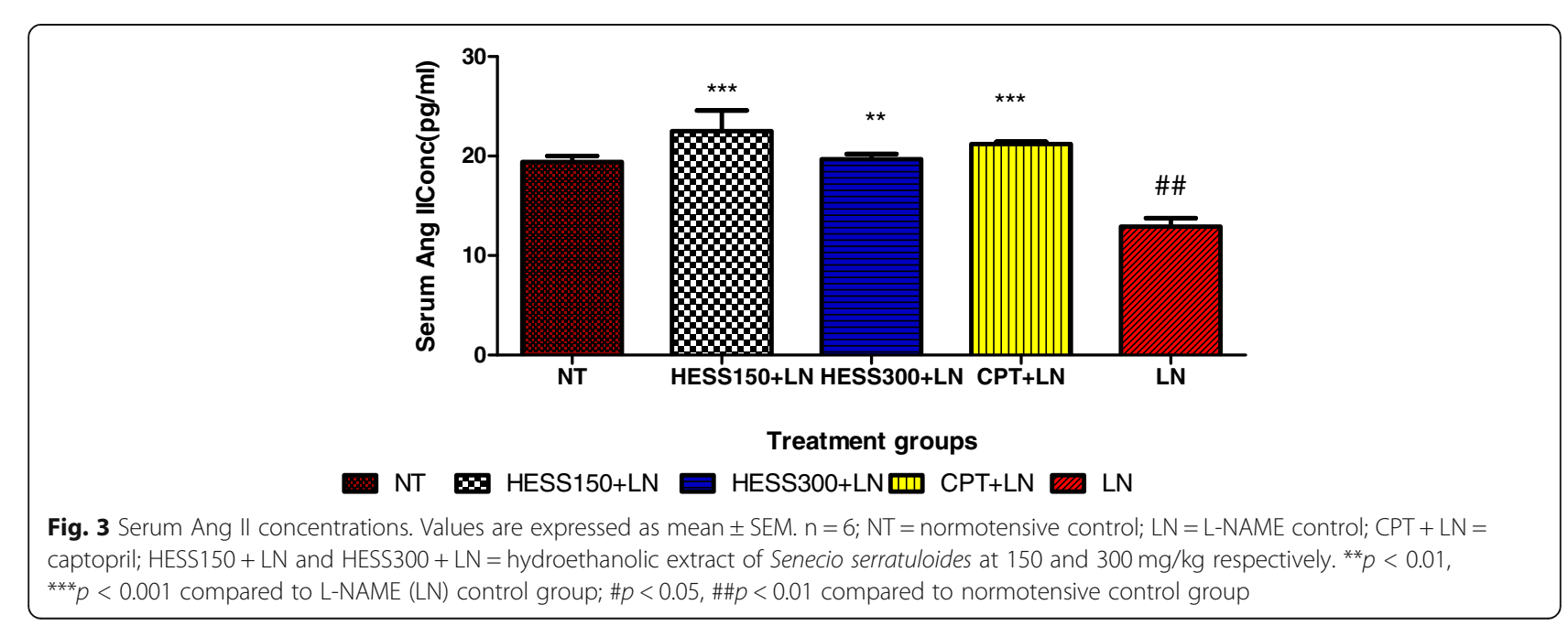




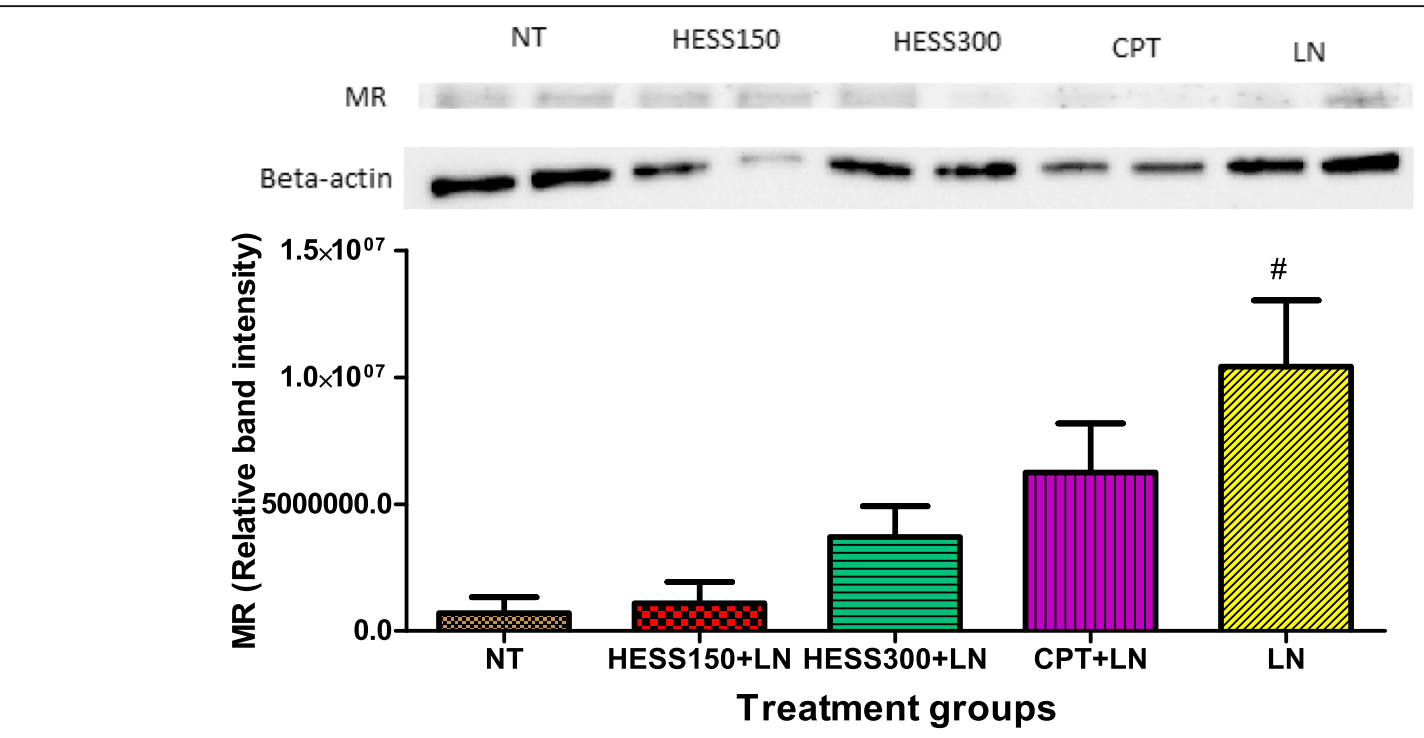

Fig. 4 Western blot analysis of mineralocorticoid receptors expression in kidneys of treated rats. The density of each band was evaluated and their ratios to $\beta$-actin measured. $M R=$ mineralocorticoid receptor; $L N=L-N A M E$ control; $C P T+L N=$ captopril; HESS150 + LN and HESS300 + LN =

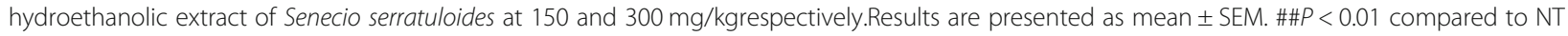
control group

improved HDL. This was confirmed by its ability to prevent L-NAME induced decrease in serum NO levels. In the heart and kidneys however, the concentration of $\mathrm{NO}$ in L-NAME groups was comparable to normotensive control. This finding was consistent with previous studies by Adaramoye et al. [38] and Berkban et al. [39] who also observed normal levels of $\mathrm{NO}$ in heart and kidney of L-NAME treated rats. Abdel-Raham et al. [40] proposed that eNOS protein expression may be up-regulated in L-NAME treated rats as a counter-regulatory mechanism to compensate for increased BP. On the other hand Luvarà et al. [41] showed that chronic L-NAME administration was associated with the induction of iNOS expression both at mRNA and protein level. Inducible NOS-derived NO is implicated in the pathogenesis of tissue injury [42] probably through the formation of peroxynitrite and ROS suggesting the pathology observed in cardiac tissue of L-NAME treatment group despite the $\mathrm{NO}$ availability. However this finding was inconsistent with Talas et al. [43] who reported decrease in NO concentration in heart and kidney after L-NAME treatment for 15 days. This divergence in findings may be due to differences in duration of studies, dose of L-NAME administered and/or route of administration. In our finding, CPT improved NO availability in the absence of HDL improvement. Similarly, Bernátová et al. [44] showed improved

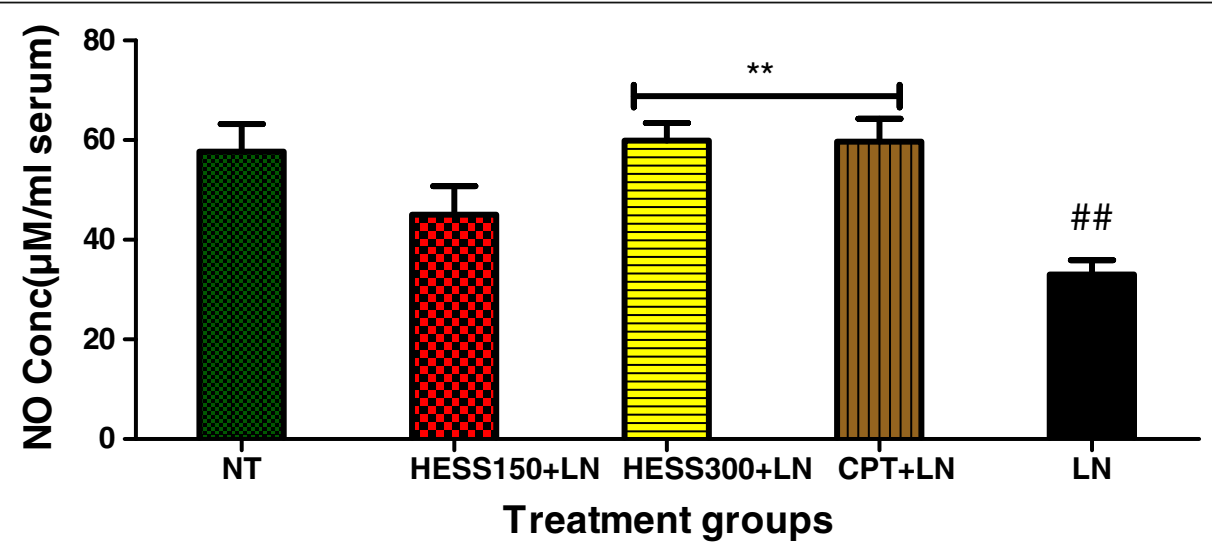

Fig. 5 Serum concentration of NO. Values are expressed as mean \pm SEM. $n=6$; NT= normotensive control; LN=L-NAME control; CPT + LN= captopril; HESS150 + LN and HESS300 + LN = hydroethanolic extract of Senecio serratuloides at 150 and $300 \mathrm{mg} / \mathrm{kg}$ respectively. ${ }^{* *} p<0.01$ compared to L-NAME (LN) control group; \#\#p<0.01 compared to normotensive control group 

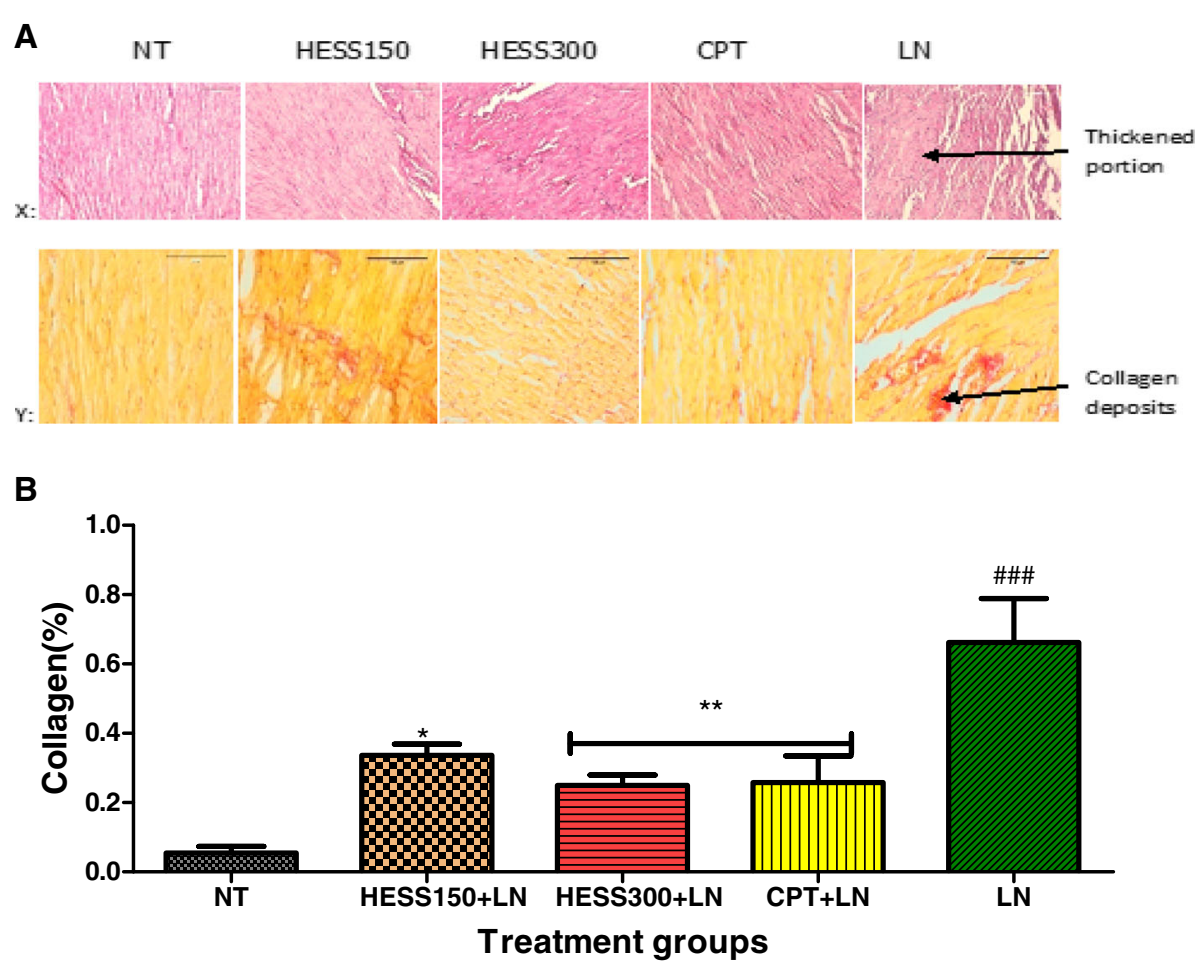

Fig. 6 Representative photomicrographs (a) of cardiac tissue and graph of semi-quantitative analysis of collagen (b). (X)- sections stained with haematoxylin (magnification $\times 20$ ) and eosin; $(Y)$ - sections stained with picrosirius red stain (magnification $\times 40$ ); NT- normotensive control; HESShydroethanolic extract of S. serratuloides at 150 and $300 \mathrm{mg} / \mathrm{kg}$; CPT-captopril group; LN-L-NAME group. Values are expressed as mean \pm SEM. ${ }^{*} p<0.05 ;{ }^{* *} P<0.01$ versus $L N$ control; \#\#\#p $<0.001$ versus NT control

tissue specific NOS activity with CPT at the higher dose of $100 \mathrm{mg} / \mathrm{kg}$, contrary to that reported by Pechanova et al. [45] in which a similar dose of CPT failed to reverse L-NAME induced NO depletion. We have no explanation for this difference at the present moment but it may be worthwhile to investigate $\mathrm{CPT}$ effects in a dose response manner.

In this study L-NAME suppressed serum Ang II production thus confirming the finding of Johnson and Freeman [46] who showed that L-NAME decreases serum Ang II concentration. The ability of HESS to maintain serum Ang II at normal levels suggested that it decreased BP by maintaining a balance between Ang II and NO. Endothelial cells generate both Ang II and NO which both have antagonistic effects on vascular smooth muscle cell [47]. Therefore, a balance in concentration of the two molecules is important for maintaining homeostasis.

L-NAME-induced increase in mineralocorticoid receptor concentration in the kidney observed in this study was in line with previous reports that indicated that L-NAME treatment activated the renal renin angiotensin system (RAS) [48] while cardiac hypertrophy was also observed in L-NAME treated rats [49]. These findings suggested the existence of systemic as well as renal RAS thus corroborating studies by Giani et al. [46] which confirmed that
L-NAME treated rats are a model of low plasma renin hypertension. These researchers further showed that L-NAME induced a marked activation of the renal RAS in wild-type mice which was absent in the angiotensin converting enzyme (ACE) mutant mice. Angiotensin converting enzyme is the target of ACE inhibitors, which are important medications in the treatment of both L-NAME induced HTN and human essential HTN. The endothelial lining of the lungs is considered the main source of $\mathrm{ACE}$ hence it is believed that ACE inhibitors lower BP by inactivating endothelial ACE [50]. However, findings from this study and the fact that many hypertensive patients have normal or low renin levels [51,52] contradicted this belief. In addition, ACE inhibitors still reduce BP in patients with normal plasma angiotensin II levels [48] further suggesting that the source of ACE may not be limited to the endothelium. Furthermore, besides endothelial ACE, large amounts of ACE are synthesized locally in tissues particularly in the kidney, with potentially broad influences on renal function and ultimately BP [53]. Previous reports by Quiroz et al. [54] and Graciano et al. [48] showed that L-NAME increased renal abundance of several local RAS components, including angiotensinogen, ACE, and the AT1 receptor. Consequently, several authors proposed that intra-renal RAS activation may play a major role in the development 
of HTN and renal injury, even when there is no clear evidence of increased systemic RAS $[46,55]$. This may be due to L-NAME-driven renal inflammation and oxidative stress which can override the physiologic regulation of the local renal RAS and induce its activation [42, 50]. A similar mechanism may explain the effects of L-NAME in cardiac tissue. The role of HESS in treating HTN was further supported by its ability to prevent cardiac hypertrophy and L-NAME induced increase in mineralocorticoid receptor concentration in the kidney in a dose dependent manner. The cardio-protective effect of HESS may have been through inhibition of inflammation and oxidative stress and hence preventing the elevation of RAS components in the heart. Indeed, this plant has been shown to have anti-inflammatory, anti-antioxidant [13] and wound healing effects [14].

\section{Conclusion}

The findings in this study demonstrated that S. serratuloides crude extract significantly reduced L-NAME-induced hypertension and L-NAME-induced changes in regulators of blood pressure like nitric oxide and angiotensin II thus showing great therapeutic potential for hypertension.

\begin{abstract}
Abbreviations
ACE: angiotensin converting enzyme; Ang II: Angiotensin II; AT1: angiotensin receptor type 1; CPT: Captopril (20 mg/kg); CVD: cardiovascular disease; $\mathrm{D}_{0}$ : Dose killing no animal; $\mathrm{D}_{100}$ : Dose killing all animals; DBP: diastolic blood pressure; eNOS: endothelial nitric oxide synthase; HESS: hydroethanol extract of S. serratuloides; HESS150: HESS (150 mg/kg); HESS300: HESS (300 mg/kg); HRP: horseradish peroxidase; HTN: hypertension; iNOS: inducible nitric oxide synthase; LD 50 : Lethal Dose 50; LN: L-NAME; L-NAME: N-Nitro-L-arginine methyl ester; NEDD: N-(1-naphthyl) ethylenediamine; NO: Nitric oxide; NT: normotensive control; oxLDL: oxidized Low density lipoprotein cholesterol; RAS: renin angiotensin system; ROS: reactive oxygen species; SBP: Systolic blood pressure; TC: HDL + LDL + VLDL
\end{abstract}

\section{Acknowledgements}

The authors are thankful to Dr. Immelman of the KEI Herbarium - Walter Sisulu University for identifying the plant used in this study. We thank Mrs Mathulo Shauli of the Department of Human Biology, Walter Sisulu University for assistance with histology.

\section{Funding}

This work was supported by the National Research Foundation (NRF Grant UID 93177), South Africa and the National Institute of Minority Health and Health Disparities/National Institutes of Health (Grant \# 5T37MD001810).

\section{Availability of data and materials}

All data described in this manuscript are available from the corresponding author on reasonable request.

\footnotetext{
Authors' contributions

CM T: collected data, analyzed data, prepared first manuscript draft. CRS-R: participated in designing the study, taught lead author techniques used in research, participated in data analysis and interpretation of results. OOO: participated in designing the study, participated in editing first draft of manuscript. ETG: participated in designing the study, sourced funding and edited first manuscript. FM: participated in designing the study and applying for funding, provided biological materials for study. BNN-C: participated in designing the study, sourced funding, oversaw data collection process, prepared final draft of manuscript and submitted for publication. All authors have read and approved the manuscript.
}

\section{Authors' information}

Not applicable.

\section{Ethics approval and consent to participate}

All procedures in this study were performed in accordance with the South African National Standard for the Care and Use of Animals for Scientific Purpose (SANS 10386:2008). Ethical approval was obtained from the Walter Sisulu University Health Sciences Research and Ethics Committee (Protocol \# 051/15).

\section{Consent for publication}

Not applicable.

\section{Competing interests}

The authors declare no competing interests.

\section{Publisher's Note}

Springer Nature remains neutral with regard to jurisdictional claims in published maps and institutional affiliations.

\section{Author details}

${ }^{1}$ Department of Human Biology, Faculty of Health Sciences, Walter Sisulu University, Mthatha 5117, South Africa. ${ }^{2}$ Department of Chemistry, Faculty of Science and Agriculture, University of Fort Hare, PBX1314, Alice, Eastern Cape Province 5700, South Africa. ${ }^{3}$ Department of Chemistry, Faculty of Science and Technology, Rusangu University, Monze, Zambia. ${ }^{4}$ Traditional Healer, Lusikisiki, Eastern Cape, South Africa. ${ }^{5}$ Department of Biological Sciences, Faculty of Natural Sciences, Walter Sisulu University, Mthatha 5117, South Africa.

Received: 13 December 2018 Accepted: 21 February 2019 Published online: 28 February 2019

\section{References}

1. World Health Organization. A global brief on hypertension: silent killer, global public health crisis: World Health Day 2013. Available from: http://ish-world. com/downloads/pdf/global_brief_hypertension.pdf [Accessed 21 March 2018].

2. Seedat YK. Hypertension in black south Africans. J Hum Hypertens. 1999; 13(2):97-103.

3. Ettehad D, Emdin CA, Kiran A, Anderson SG, Callender T, Emberson J, et al. Blood pressure lowering for prevention of cardiovascular disease and death: a systematic review and meta-analysis. The Lancet. 2016;5:387(10022):957-67.

4. Karnes JH, Cooper-DeHoff RM. Antihypertensive medications: benefits of blood pressure lowering and hazards of metabolic effects. Expert Rev Cardiovasc Ther. 2009;7(6):689-702.

5. Benzie IF, Wachtel-Galor S, editors. Herbal medicine: biomolecular and clinical aspects. CRC Press; 2011.

6. Alamgir AN. Therapeutic use of medicinal plants and their extracts: volume 1: Springer; 2017.

7. De Wet H, Nciki S, van Vuuren SF. Medicinal plants used for the treatment of various skin disorders by a rural community in northern Maputaland. South Africa J Ethnobiol Ethnomed. 2013;9(1):51

8. De Wet H, Nzama VN, Van Vuuren SF. Medicinal plants used for the treatment of sexually transmitted infections by lay people in northern Maputaland, KwaZulu-Natal Province, South Africa. S Afr J Bot. 2012;78:12-20.

9. De Wet $\mathrm{H}$, Ramulondi M, Ngcobo ZN. The use of indigenous medicine for the treatment of hypertension by a rural community in northern Maputaland, South Africa. S Afr J Bot. 2016;103:78-88.

10. Van Wyk BE. The potential of south African plants in the development of new medicinal products. S Afr J Bot. 2011;77(4):812-29.

11. Ramulondi M. Toxicology and herb-drug interaction of selected antihypertension plants used by lay persons in Northern KwaZulu-Natal (South Africa). 2016 (Doctoral dissertation, University of Zululand).

12. York T, De Wet H, Van Vuuren SF. Plants used for treating respiratory infections in rural Maputaland, KwaZulu-Natal. South Africa J Ethnopharmacol. 2011; 135(3):696-710.

13. Fawole OA, Amoo SO, Ndhlala AR, Light ME, Finnie JF, Van Staden J. Antiinflammatory, anticholinesterase, antioxidant and phytochemical properties of medicinal plants used for pain-related ailments in South Africa. J Ethnopharmacol. 2010;127(2):235-41, 
14. Gould AN, Penny CB, Patel CC, Candy GP. Enhanced cutaneous wound healing by Senecio serratuloides (Asteraceae/Compositae) in a pig model. S Afr J Bot. 2015;100:63-8.

15. Cifuentes F, Paredes A, Palacios J, Muñoz F, Carvajal L, Nwokocha CR, et al. Hypotensive and antihypertensive effects of a hydroalcoholic extract from Senecio nutans Sch. Bip.(Compositae) in mice: chronotropic and negative inotropic effect, a nifedipine-like action. J Ethnopharmacol. 2016;179:367-74.

16. Lee LS, Cho CW, Hong HD, Lee YC, Choi UK, Kim YC. Hypolipidemic and antioxidant properties of phenolic compound-rich extracts from white ginseng (Panax ginseng) in cholesterol-fed rabbits. Molecules. 2013;18(10):12548-60.

17. Ajiboye BO, Edobor G, Ojo AO, Onikanni SA, Olaranwaju Ol, Muhammad NO. Effect of aqueous leaf extract of Senecio biafrae on hyperglycaemic and serum lipid profile of alloxan-induced diabetic rats. Int J of Dis Disorders. 2014;2(1):59-64.

18. Bernatova I. Endothelial dysfunction in experimental models of arterial hypertension: cause or consequence? Biomed Res Int. 2014;2014:Article ID 598271

19. Biancardi VC, Bergamaschi CT, Lopes OU, Campos RR. Sympathetic activation in rats with L-NAME-induced hypertension. Braz J Med Biol Res. 2007:40(3):401-8.

20. Mata-Greenwood E, Chen DB. Racial differences in nitric oxide-dependent Vasorelaxation. Reproduct Sci. 2008;15(1):9-25.

21. Zambrano S, Blanca AJ, Ruiz-Armenta MV, Miguel-Carrasco JL, Arévalo M, Mate $A$, et al. L-carnitine attenuates the development of kidney fibrosis in hypertensive rats by upregulating PPAR- $\gamma$. Am J Hyperten. 2014;27(3):460-70.

22. South African National Standard: The care and use of animals for scientific purposes. (SANS10386: 2008).

23. Bulus T, Atawodi SE, Mamman M. Acute toxicity effects of the aqueous extract of Terminalia avicennioides on the white albino rats. World Science Journal. 2011;6:1-4.

24. Lane, N. Effects of Heme-L-Arginate on L-NAME-induced Hypertension. 2012. MSc. University of Saskatchewan, Canada.

25. Maghrani M, Zeggwagh NA, Michel JB, Eddouks M. Antihypertensive effect of Lepidium sativum $\mathrm{L}$. in spontaneously hypertensive rats. J Ethnopharmacol. 2005;100(1-2):193-7.

26. Ribeiro RM, Pinheiro NVF, Ribeiro KS, Vieira DA, Abreu IC, Silva SD, et al. Antihypertensive effect of Syzygium cumini in spontaneously hypertensive rats. Evid Based Complement Alternat Med. 2014;2014: Article ID 605452.

27. Vuilleumier N, Bratt J, Alizadeh R, Jogestrand T, Hafström I, Frostegård J. Anti-apoA-1 IgG and oxidized LDL are raised in rheumatoid arthritis (RA): potential associations with cardiovascular disease and RA disease activity. Scand J Rheumatol. 2010;39(6):447-53.

28. Giri, D., 2015. Haematoxylin and eosin staining: principle, procedure and interpretation. [cited April 4]. Available from: http://www.laboratoryinfo.com [Accessed 21 March 2017].

29. Dapson RW, Fagan C, Kiernan JA, Wickersham TW. Certification procedures for sirius red F3B (Cl 35780, direct red 80). Biotech Histochem. 2011;86(3):133-9.

30. Hmaid AA, Markelic M, Otasevic V, Masovic S, Jankovic A, Korac B, Korac A. Structural alterations in rat myocardium induced by chronic l-arginine and INAME supplementation. Saudi J Biol Sci. 2016;25(3):537-44.

31. Hadi AM, Mouchaers KT, Schalij I, Grunberg K, Meijer GA, Vonk-Noordegraaf A, et al. Rapid quantification of myocardial fibrosis: a new macro-based automated analysis. Cell Oncol. 2011;34(4):343-54.

32. Konaté $\mathrm{K}$, Yomalan $\mathrm{K}$, Sytar $\mathrm{O}$, Zerbo $\mathrm{P}$, Brestic M, Patrick VD, et al. Free radicals scavenging capacity, antidiabetic and antihypertensive activities of flavonoid-rich fractions from leaves of Trichilia emetica and Opilia amentaced in an animal model of type 2 diabetes mellitus. Evid Based Complement Alternat Med. 2014;2014: Article ID 867075.

33. Salam MA, Ibrahim BM, El-Batran SE, El-Gengaihi SE, Baker DH. Study of the possible antihypertensive and hypolipidemic effects of an herbal mixture on I-name-induced hypertensive rats. Asian J Pharm Clin Res. 2016;9(5):85-90.

34. Shu X, Keller TS, Begandt D, Butcher JT, Biwer L, Keller AS, et al. Endothelial nitric oxide synthase in the microcirculation. Cell Mol Life Sci. 2015;72(23):4561-75.

35. Shaul PW. Endothelial nitric oxide synthase, caveolae and the development of atherosclerosis. J Physiol. 2003;547(1):21-33 Wall: prevention by angiotensin II antagonism. Arterioscler Thromb Vasc Biol 1998;18(9):1408-16.

36. Förstermann $U$, Münzel $T$. Endothelial nitric oxide synthase in vascular disease: from marvel to menace. Circulation. 2006;113(13):1708-14.

37. Talas ZS, Ozdemir I, Ciftci O, Cakir O, Gulhan MF, Pasaoglu OM. Role of propolis on biochemical parameters in kidney and heart tissues against LNAME induced oxidative injury in rats. Clin Exp Hypertens. 2014;36(7):492-6.
38. Adaramoye OA, Nwosu IO, Farombi EO. Sub-acute effect of NG-nitro-Iarginine methyl-ester (L-NAME) on biochemical indices in rats: protective effects of Kolaviron and extract of Curcuma longa L. Pharm Res. 2012;4(3):127.

39. Berkban T, Boonprom P, Bunbupha S, Welbat JU, Kukongviriyapan U, Kukongviriyapan $\mathrm{V}$, et al. Ellagic acid prevents L-NAME-induced hypertension via restoration of eNOS and p47phox expression in rats. Nutrients. 2015;7(7):5265-80.

40. Abdel-Raham RA, Abdelbaset M, Abd-Elsalam RM, Hessin A, Ogaly HA Hassan SM. Antihypertensive effects of Roselle-olive combination in L-NAME induced hypertensive rats. Oxidative Med Cell Longev. 2017;12(1):1-24.

41. Luvara G, Pueyo ME, Phillipe M, Mandet C, Savoie F, Henrion D, Michel JB. Chronic blockade of NO synthase activity induces a proinflammatory phenotype in the arterial wall: prevention by angiotensin II antagonism. Arterioscler Throm Vasc Biol. 1998;18(9):1408-16.

42. Giani JF, Janjulia T, Kamat N, Seth DM, Blackwell WL, Shah KH, et al. Renal angiotensin-converting enzyme is essential for the hypertension induced by nitric oxide synthesis inhibition. J Am Soc Nephrol. 2014;10:ASN2013091030.

43. Talas Z, Ozdemir I, Ciiftci O, Cakir O, Gulhan M, Pasaoglu O. Role of Propolis on biochemical parameters in kidney and heart tissue against L-NAMEinduced oxidative injury in rats. Clin Exp Hypertens. 2014;36(7):492-6.

44. Bernátová I, Pechánová OG, Simko F. Effect of captopril in L-NAME-induced hypertension on the rat myocardium, aorta, brain and kidney. Exp Physiol. 1999;84(6):1095-105.

45. Pechanova O, Matuskova J, Capikova D, Jendekova L, Paulis L, Simko F. Effect of spironolactone and captopril on nitric oxide and S-nitrosothiol formation in kidney of L-NAME-treated rats. Kidney Int. 2006;70(1):170-6.

46. Johnson RA, Freeman $\mathrm{RH}$. Renin release in rats during blockade of nitric oxide synthesis. Am J Physiol. 1994;266:R1723-9.

47. Millatt $\amalg$, Abdel-Rahman EM, Siragy HM. Angiotensin II and nitric oxide: a question of balance. Regul Pept. 1999;81(1-3):1-10.

48. Graciano ML, de Cassia CR, Dellê H, Dominguez WV, Casarini DE, Malheiros $\mathrm{DM}$, et al. Intrarenal renin-angiotensin system is upregulated in experimental model of progressive renal disease induced by chronic inhibition of nitric oxide synthesis. J Am Soc Nephrol. 2004;15(7):1805-15.

49. Sung JH, Jo YS, Kim SJ, Ryu JS, Kim MC, Ko HJ, et al. Effect of lutein on LNAME-induced hypertensive rats. Kor J Physio Pharmaco. 2013;17(4):339-45.

50. Moon JY. Recent update of renin-angiotensin-aldosterone system in the pathogenesis of hypertension. Electrolytes Blood Press. 2013;11(2):41-5.

51. Atlas SA. The renin-angiotensin aldosterone system: pathophysiological role and pharmacologic inhibition. J Manag Care Pharm. 2007;13(8 Supp B):9-20.

52. Alderman MH, Cohen HW, Sealey JE, Laragh JH. Plasma renin activity levels in hypertensive persons: their wide range and lack of suppression in diabetic and in most elderly patients. Am J Hypertens. 2004;17(1):1-7.

53. Admiraal PJ, van Eck RHJ, Boomsma F, Derkx FH, Schalekamp MA. Partial escape of angiotensin converting enzyme (ACE) inhibition during prolonged ACE inhibitor treatment: does it exist and does it affect the antihypertensive response? J Hypertens. 1992;10(8):803-12.

54. Quiroz Y, Pons H, Gordon KL, Rincón J, Chávez M, Parra G, et al. Mycophenolate mofetil prevents salt-sensitive hypertension resulting from nitric oxide synthesis inhibition. Am J Physiol Renal Physiol. 2001;281(1):F38-47.

55. Sousa T, Oliveira S, Afonso J, Morato M, Patinha D, Fraga S, Carvalho F, Albino-Teixeira A. Role of $\mathrm{H} 2 \mathrm{O} 2$ in hypertension, renin-angiotensin system activation and renal medullary dysfunction caused by angiotensin $\mathrm{I} . \mathrm{Br}$ J Pharmacol. 2012;166(8):2386-401

\section{Ready to submit your research? Choose BMC and benefit from:}

- fast, convenient online submission

- thorough peer review by experienced researchers in your field

- rapid publication on acceptance

- support for research data, including large and complex data types

- gold Open Access which fosters wider collaboration and increased citations

- maximum visibility for your research: over $100 \mathrm{M}$ website views per year

At $\mathrm{BMC}$, research is always in progress.

Learn more biomedcentral.com/submission 